The International Journal of Engineering and Science (IJES)

|| Volume || 6 || Issue || 6 || Pages || PP 70-77 || 2017 ||

ISSN (e): $2319-1813 \operatorname{ISSN}(\mathrm{p}): 2319-1805$

\title{
Literacy Level in Andhra Pradesh and Telangana States - A Statistical Study
}

\author{
K. Kumaraswamy, C. Jayalakshmi \\ Department of Statistics, Osmania University - Hyd.
}

\begin{abstract}
Literacy is the most important aspect for progress of people in a country. Higher is the literacy level, more is the civilization of the race. Keeping this in view, we took up a comparative study on female literacy levels in the Andhra Pradesh \& Telangana states for Urban and Rural areas separately from $1991-2011$. The study and analysis is based on secondary data collected from the Census Office of the above states. We used the statistical tools - Shewartz Control Charts for identify Very Poor and Moderately Poor districts w.r.t., female literacy ratio. The analysis, comparisons and conclusions are presented in this paper. More specifically, we wish to state that female literacy has a direct impact on growth of a family.
\end{abstract}

Keywords: Literacy ratio, Education level, Very poor, Moderately poor and Control Chart

Date of Submission: 05 June 2017

Date of Accepted: 22 June 2017

\section{I-INTRODUCTION}

Literacy is the very foundation for the development of the people and universalization of literacy must receive the highest priority. Literacy is the most important determinant for the progress of any country. A great many people in India cannot even read or write. Our country cannot progress if the majority of the people are ignorant and uneducated.

Early literacy is the first step to education, this is the stage where the three R's (Reading, Writing and Arithmetic) are taught and this is the minimum basic need for every civilized person. It involves all round early education of a child inclusive of what he is taught at home, pre-schools and elementary schools. If the people can read and write they will learn to think and speak. This is the way of giving voice to dumb millions. Further it has been observed, studied and exhibited that these statements inspired us to look into the scenario of literacy levels in that two Telugu states Andhra Pradesh (AP) and Telangana State (TS).

\section{Definition of literacy:}

Definition-1: The United Nations Educational, Scientific, and Cultural Organization (UNESCO) has drafted a definition of literacy as the "ability to identify, understand, interpret, create, communicate, compute and use printed and written materials with varying contexts".

Definition-2: The National Literacy Mission defines literacy as "acquiring the skills of reading, writing and arithmetic and the ability to apply them to one's day-to-day life".

\section{Literacy in India:}

Education is a key for socio-economic progress, and the Indian literacy rate has grown to $74.04 \%$ (2011 figure) from $12 \%$ at the end of British rule in 1947. Although this was greater than six fold improvement, the level is below the world average literacy rate of $84 \%$ and of all nations in the world, India currently has the largest illiterate population. Female literacy rate has a direct impact on population stabilization. Education, being the most fundamental need of any developing country, its promotion should be the number one priority for India. According to 2011 census compilation Andhra Pradesh (AP) is ranked 32 and Telangana State (TS) is ranked as 35 among Indian states and Union Territories and their overall literacy percentages are 67.4 and 66.5 respectively.

II-About the data:

The data is collected from Directorate of Census Operations, Govt. of AP \& TS, Hyderabad. In Census 2011, 2001 as well as in 1991 data is collected on literacy for different educational levels, exhaustively, for different age groups starting from7 years to 80+ years. In Census 2001 \&n2011 literacy levels are categorized the as

1. Literate without educational level

2. Below Primary

3. Level not classified

4. Primary

5. Middle 
6. Secondary/Metric

7. Higher Secondary/Intermediate/Pre-University/Senior Secondary

8. Non-Technical Diploma/Certificate of Diploma not equal to Degree

9. Technical Diploma/Certificate of Diploma not equal to Degree

10. Graduate and above.

In Census 1991 also the categorization differs on at below Primary levels. From Primary onwards the same categorization was observed. Under "Literate without educational level" two categories are considered as "Formal" and "Non-formal" education. The categories "Below Primary" and "Level not classified" were not considered.

In this analysis the categories "Literate without educational level", "Below Primary", "Level not classified" and "Primary" of Census 1991-2011 are pooled and put under "Primary" level of education. Similarly in Census 1991 the categories "Literate without educational level-Formal, Non-formal" and "Primary" are pooled and called "Primary". In all the three Census the categories 7, 8 and 9 were pooled and presented under "PreUniversity" level of education. This pooling is felt relevant as these categories broadly represent similar level of education. So, in this analysis there are only 5 levels of education, viz., Primary, Middle, Secondary, PreUniversity, Graduate.

\section{DIFFERENT LITERACY LEVELS}

When different levels of literacy is considered literacy ratio is inversely proportional to the level of education. When the education level increases literacy ratio decreases. Tables $1 \& 2$ given below show these ratios for all districts of AP and TS in Rural \& Urban areas.

\begin{tabular}{|c|c|c|c|c|c|}
\hline District & Primary & Middle & Secondary & Pre-Univ. & Grad. \& above \\
\hline Adilabad & 632 & 486 & 394 & 292 & 206 \\
\hline Nizamabad & 563 & 521 & 428 & 327 & 236 \\
\hline Karimnagar & 684 & 550 & 436 & 327 & 232 \\
\hline Medak & 627 & 493 & 400 & 287 & 218 \\
\hline Hyderabad & $*$ & $*$ & $*$ & $*$ & $*$ \\
\hline Rangareddy & 658 & 550 & 432 & 332 & 288 \\
\hline Mahbubnagar & 606 & 494 & 389 & 298 & 231 \\
\hline Nalgonda & 680 & 554 & 455 & 326 & 216 \\
\hline Warangal & 697 & 568 & 431 & 313 & 206 \\
\hline Khammam & 757 & 623 & 534 & 379 & 294 \\
\hline Srikakulam & 729 & 569 & 437 & 302 & 197 \\
\hline Vizianagaram & 682 & 504 & 416 & 296 & 220 \\
\hline Visakhapatnam & 717 & 547 & 419 & 300 & 284 \\
\hline East Godavari & 983 & 758 & 628 & 385 & 316 \\
\hline West Godavari & 985 & 800 & 678 & 425 & 367 \\
\hline Krishna & 927 & 715 & 597 & 433 & 419 \\
\hline Guntur & 799 & 644 & 544 & 389 & 323 \\
\hline Prakasam & 694 & 535 & 436 & 322 & 258 \\
\hline Y.S.R. & 804 & 610 & 555 & 398 & 321 \\
\hline Kurnool & 699 & 527 & 440 & 325 & 241 \\
\hline Anantapur & 627 & 476 & 377 & 281 & 228 \\
\hline Chittoor & 618 & 510 & 460 & 343 & 216 \\
\hline
\end{tabular}

Table 1: District wise Rural average literacy ratio

\begin{tabular}{|c|c|c|c|c|c|}
\hline District & Primary & Middle & Secondary & Pre-Univ. & Grad. \& above \\
\hline Adilabad & 889 & 818 & 652 & 477 & 356 \\
\hline Nizamabad & 918 & 866 & 718 & 573 & 386 \\
\hline Karimnagar & 952 & 832 & 679 & 504 & 363 \\
\hline Medak & 945 & 865 & 688 & 470 & 503 \\
\hline Hyderabad & 954 & 925 & 819 & 723 & 567 \\
\hline Rangareddy & 954 & 924 & 783 & 595 & 530 \\
\hline Mahbubnagar & 918 & 839 & 733 & 557 & 381 \\
\hline Nalgonda & 959 & 852 & 756 & 577 & 406 \\
\hline Warangal & 987 & 871 & 731 & 566 & 458 \\
\hline Khammam & 1019 & 920 & 769 & 551 & 372 \\
\hline Srikakulam & 1010 & 880 & 692 & 532 & 432 \\
\hline Vizianagaram & 1001 & 871 & 708 & 537 & 538 \\
\hline Visakhapatnam & 1033 & 916 & 713 & 501 & 488 \\
\hline East Godavari & 1120 & 955 & 772 & 579 & 480 \\
\hline West Godavari & 1120 & 988 & 807 & 598 & 547 \\
\hline Krishna & 1050 & 929 & 786 & 628 & \\
\hline
\end{tabular}


Literacy Level in Andhra Pradesh and Telangana States - A Statistical Study

\begin{tabular}{|c|c|c|c|c|c|}
\hline Guntur & 981 & 879 & 749 & 639 & 484 \\
\hline Prakasam & 980 & 840 & 689 & 523 & 411 \\
\hline Sri Potti Sriramulu Nellore & 1019 & 903 & 755 & 619 & 497 \\
\hline Y.S.R. & 906 & 795 & 653 & 553 & 384 \\
\hline Kurnool & 886 & 810 & 661 & 596 & 438 \\
\hline Anantapur & 851 & 803 & 678 & 572 & 418 \\
\hline Chittoor & 962 & 899 & 745 & 653 & 492 \\
\hline
\end{tabular}

Table 2: District wise Urban average literacy ratio

\section{STATISTICAL ANALYSIS}

We further made a study at micro level on literacy levels for 23 districts in rural and urban areas separately over a period of 20 years. The census data collected in 1991, 2001 and 2011 is used for analysis. A comparison of literacy rates is made between rural and urban areas in each district. In particular we compared female literacy ratios for every 1000 literate male under different levels of education. For these female literacy ratio's, we constructed Shewartz control charts to identify moderately poor and very poor districts at different levels for rural and urban areas. So that, Propagation of literacy awareness programs can be taken up in the Very Poor districts.

\section{Method of Constructing Control Charts:}

Since literacy level is a non-measurable characteristic. So we considered the attribute control chart "d-chart". Let $d_{i}$ be the literacy ratio's of education level, compute $\bar{d}=\frac{\sum_{i} d_{i}}{k}$; where $\mathrm{k}$ be the number of districts $i=1,2, \ldots, k$, and $\bar{p}=\frac{\bar{d}}{n}$; where $n=1000$ (for 1000 men) and $\bar{q}=1-\bar{p}$

The 3- $\sigma$ limits for Control Chart are Upper Control Limit (UCL), Central Line (CL) \& Lower Control Limit (LCL) and is given by

$$
\begin{aligned}
& U C L=n * \bar{p}+3 \sqrt{n * \bar{p} * \bar{q}} \\
& C L=n * \bar{p} \\
& L C L=n * \bar{p}-3 \sqrt{n * \bar{p} * \bar{q}}
\end{aligned}
$$

Plotting of Central Line and the Control Limits and ratios on the same graph is nothing but Construction of Control Chart. Control charts are plotted on a rectangular co-ordinate axis - ordinate representing the Statistical measure Literacy ratio, and abscissa representing the districts. If any districts ratio fall below the Lower Control Line then those districts show very poor literacy rate, and if any district ratio falls between Central Line and Lower Control Line, show moderately poor literacy. The districts fall above the Central Line and Upper Control Line, exhibit relatively higher literacy ratio.

The Control Charts for different education levels are showed below.
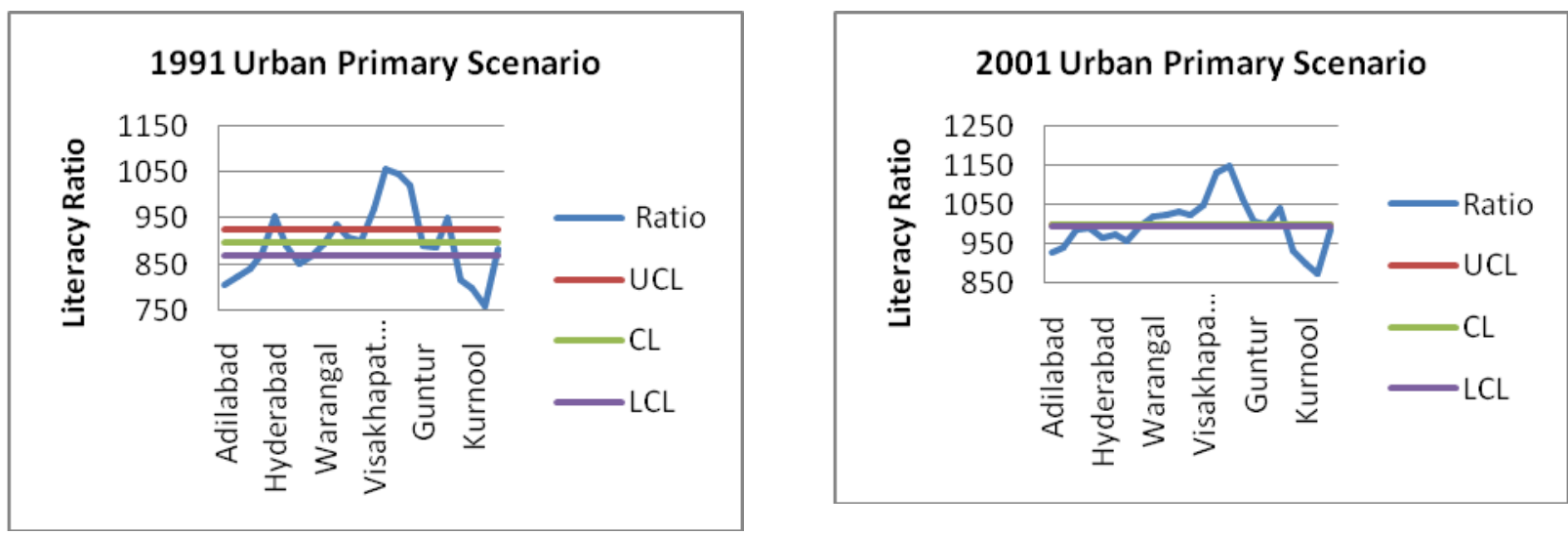
Literacy Level in Andhra Pradesh and Telangana States - A Statistical Study
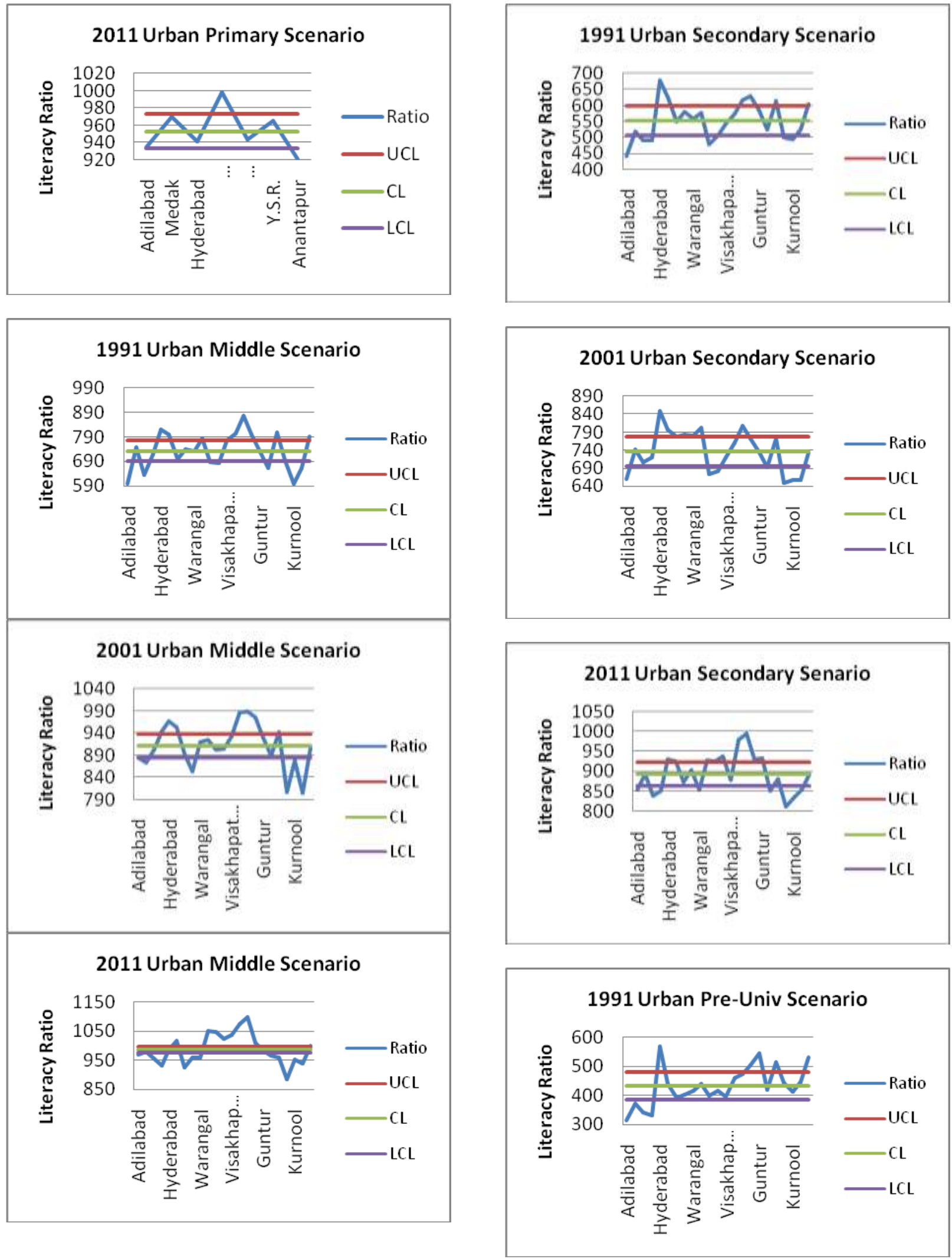

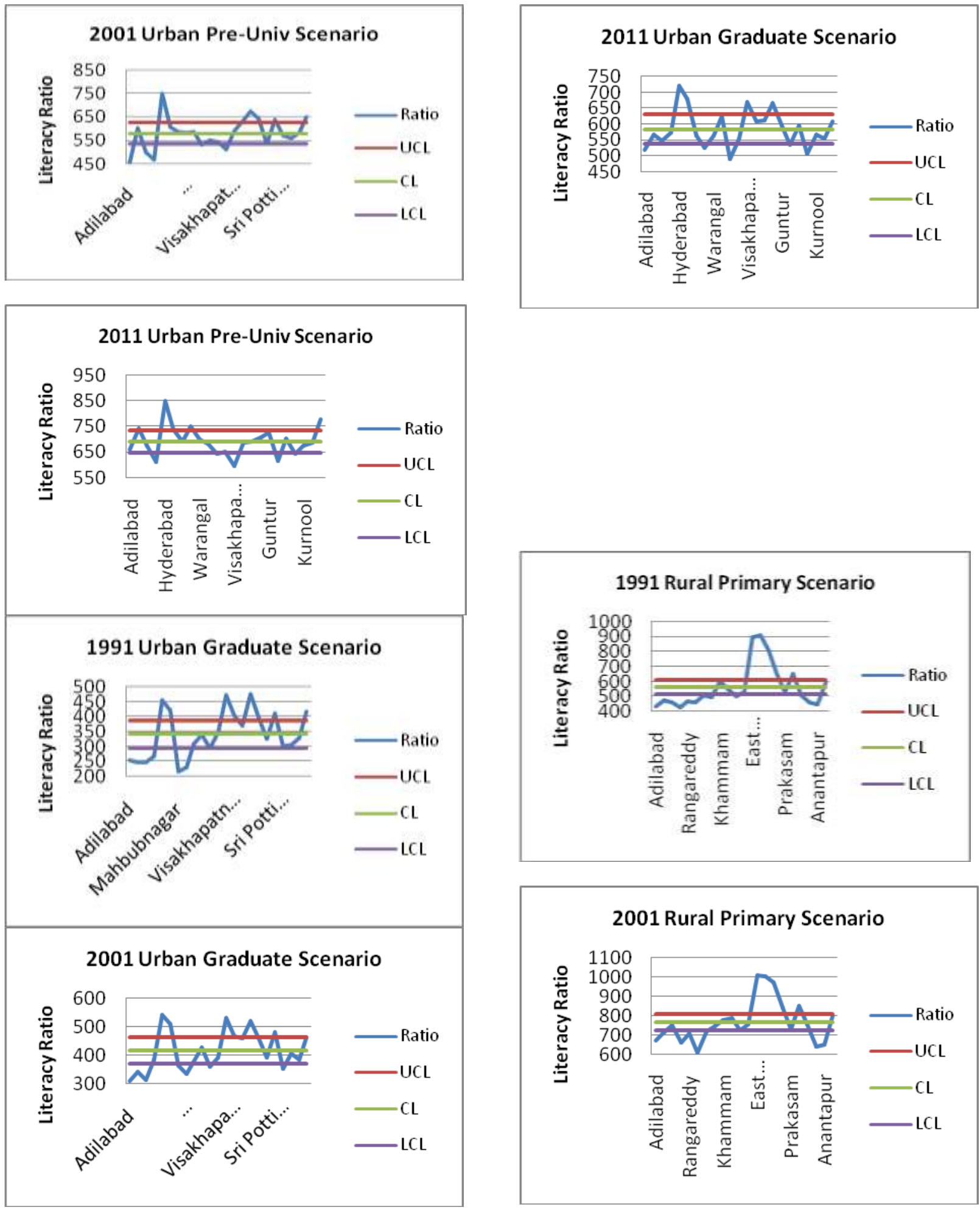

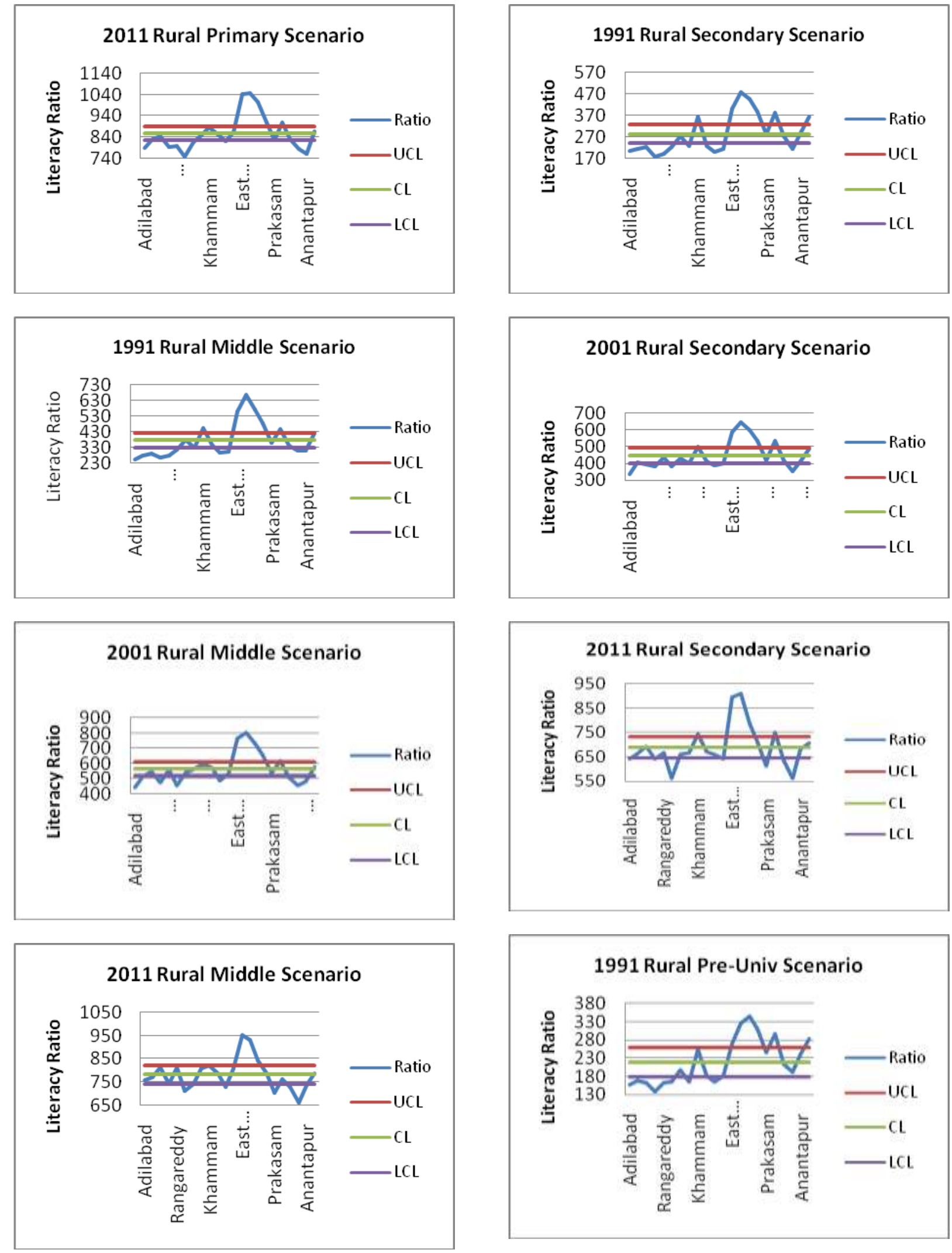

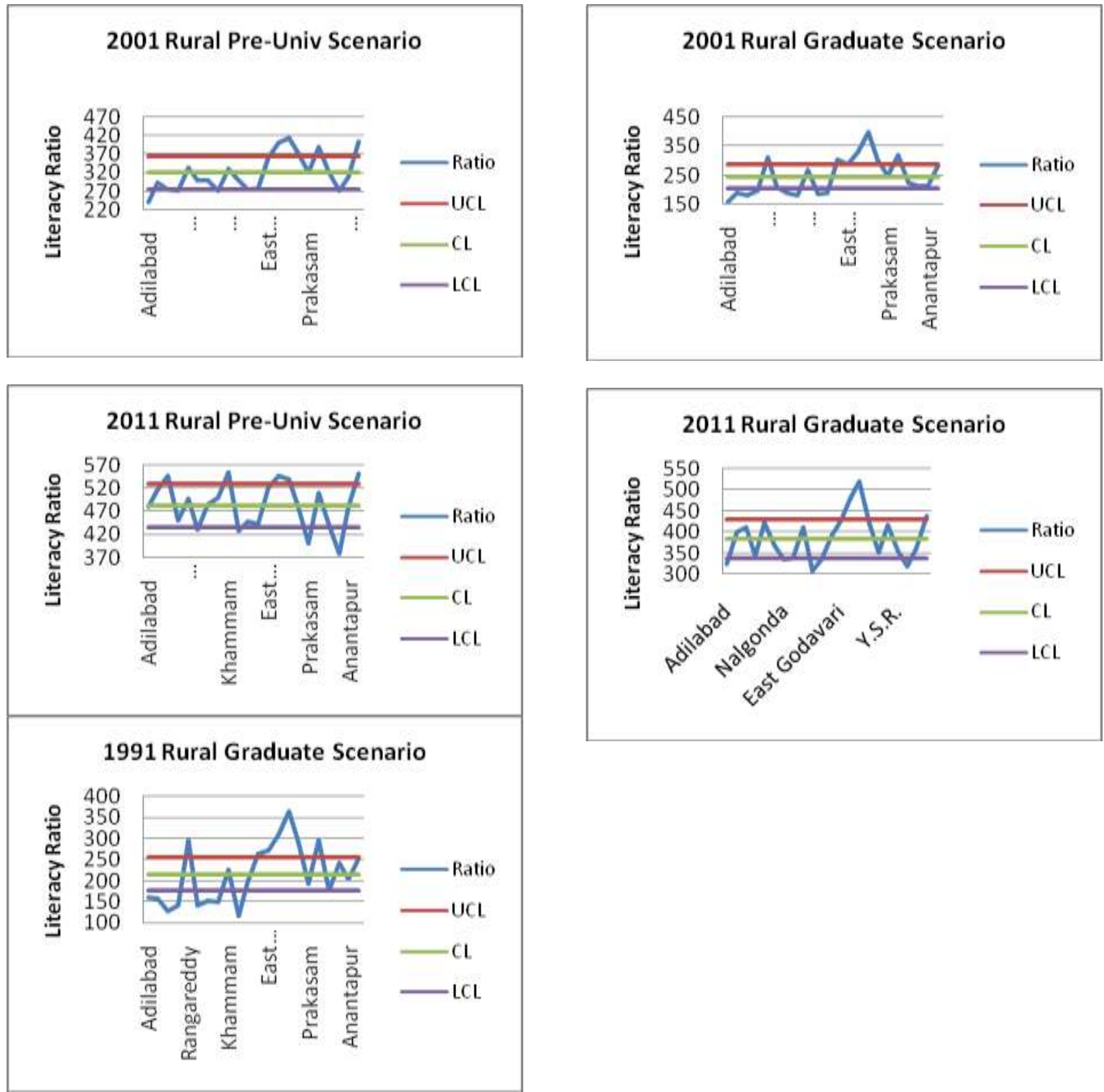

The following tables show very poor level and moderately poor level of literacy ratio exhibited in the above graphs for 1991, 2001 and 2011 Censuses in rural and urban areas.

\begin{tabular}{|c|c|c|c|}
\hline$\underset{\text { Year }}{\text { Yducation level } \downarrow} \rightarrow$ & 1991 & 2001 & 2011 \\
\hline \multicolumn{4}{|c|}{ Rural (Very Poor Level) } \\
\hline Primary & $\begin{array}{l}\text { NLG,WGL,VIZIA,YSR,ADB } \\
\text {,NZB,KNR,MDK,RR,MBNR, } \\
\text { KRNL,ANTPR }\end{array}$ & $\begin{array}{l}\text { NLG,VIZIA,ADB,NZB,MDK, } \\
\text { RR,MBNR,KRNL,ANTPR }\end{array}$ & $\begin{array}{l}\text { NLG,VIZIA,ADB,MDK,RR,MB } \\
\text { NR,KRNL,ANTPR }\end{array}$ \\
\hline Middle & $\begin{array}{l}\text { ANTPR,KRNL,ADB,NZB,K } \\
\text { NR,MDK,RR,MBNR,VIZIA, } \\
\text { VIZAG }\end{array}$ & $\begin{array}{l}\text { VIZIA,ANTPR,NZB,YSR,AD } \\
\text { B,MDK,MBNR }\end{array}$ & $\begin{array}{l}\text { VIZIA,YSR,NLG,MDK,MBNR,P } \\
\text { RKSM,KRNL,ANTPR }\end{array}$ \\
\hline Secondary & $\begin{array}{l}\text { WGL,MBNR,KRNL,SRKLM } \\
\text {,ADB,NZB,KNR,MDK,RR,V } \\
\text { IZIA,VIZAG }\end{array}$ & $\begin{array}{l}\text { VIZIA,MBNR,ADB,KNR,MD } \\
\text { K,KRNL }\end{array}$ & $\begin{array}{l}\text { VIZAG,MDK,ADB,YSR,MBNR, } \\
\text { PRKSM,KRNL }\end{array}$ \\
\hline Pre-Univ & $\begin{array}{l}\text { NZB,WGL,VIZIA,MBNR,A } \\
\text { DB,KNR,MDK,RR }\end{array}$ & KNR,MDK,WGL,KRNL,ADB & MBNR,SRKLM,PRKSM,KRNL \\
\hline Graduate & $\begin{array}{l}\text { ADB,NZB,KNR,MDK,MBN } \\
\text { R,NLG,WGL,SRKLM }\end{array}$ & $\begin{array}{l}\text { MDK,NLG,VIZIA,ADB,NZB, } \\
\text { KNR,WGL,SRKLM }\end{array}$ & $\begin{array}{l}\text { NLG,VIZIA,ADB,SRKLM,KRN } \\
\text { L,WGL }\end{array}$ \\
\hline \multicolumn{4}{|c|}{ Urban(Very Poor Level) } \\
\hline Primary & $\begin{array}{l}\text { MBNR,ADB,NZB,KNR,YSR } \\
\text {,KRNL,ANTPR }\end{array}$ & $\begin{array}{l}\text { MDK,KNR,CHTR,ADB,NZB, } \\
\text { HYD,RR,MBNR,YSR,KRNL, }\end{array}$ & ANTPR \\
\hline
\end{tabular}


Literacy Level in Andhra Pradesh and Telangana States - A Statistical Study

\begin{tabular}{|c|l|l|l|}
\hline & & ANTPR & \\
\hline Middle & $\begin{array}{l}\text { SRKLM,VIZIA,ADB,KNR,P } \\
\text { RKSM,KRNL,ANTPR }\end{array}$ & $\begin{array}{l}\text { NZB,NLG,YSR,KRNL,ANTP } \\
\text { R }\end{array}$ & $\begin{array}{l}\text { ADB,PRKSM,KNR,MDK,MBN } \\
\text { R,NLG,WGL,NLR,YSR,KRNL, } \\
\text { ANTPR }\end{array}$ \\
\hline Secondary & $\begin{array}{l}\text { YSR,KRNL,KNR,MDK,ADB } \\
\text {,SRKLM }\end{array}$ & $\begin{array}{l}\text { VIZIA,SRKLM,ADB,YSR,KR } \\
\text { NL,ANTPR }\end{array}$ & $\begin{array}{l}\text { ADB,MDK,WGL,PRKSM,ANTP } \\
\text { R,KNR,YSR,KRNL }\end{array}$ \\
\hline Pre-Univ & ADB,KNR,NZB,MDK & $\begin{array}{l}\text { KHMM,ADB,KNR,MDK,VIZ } \\
\text { AG }\end{array}$ & $\begin{array}{l}\text { SRKLM,YSR,MDK,VIZAG,PRK } \\
\text { SM }\end{array}$ \\
\hline Graduate & ADB,NZB,KNR,MDK,MBN & $\begin{array}{l}\text { MBNR,SRKLM,ADB,NZB,K } \\
\text { NR,NLG,YSR }\end{array}$ & NLG,ADB,SRKLM,YSR \\
& R,NLG & \\
\hline
\end{tabular}

Table 3: The districts exhibited Very Poor level of Education over the period of two decades

\begin{tabular}{|c|c|c|c|}
\hline$\underset{\text { Education level } \downarrow}{\text { Year }} \rightarrow$ & 1991 & 2001 & 2011 \\
\hline \multicolumn{4}{|c|}{ Rural (Moderately Poor Level) } \\
\hline Primary & SRKLM,VIZAG,PRKSM,YSR & KNR,WGL,VIZAG,PRKSM & $\begin{array}{l}\text { NZB,KNR,SRKLM,PRKSM,Y } \\
\text { SR }\end{array}$ \\
\hline Middle & $\begin{array}{l}\text { NLG,WGL,SRKLM,PRKSM,YS } \\
\mathrm{R}\end{array}$ & KNR,RR,NLG,WGL,PRKSM & NZB,NLR \\
\hline Secondary & NLG,PRKSM,YSR & $\begin{array}{l}\text { NZB,RR,NLG,WGL,SRKLM, } \\
\text { PRKSM,YSR }\end{array}$ & $\begin{array}{l}\text { NZB,RR,NLG,WGL,SRKLM, } \\
\text { ANTPR }\end{array}$ \\
\hline Pre-Univ & NLG,YSR,KRNL & $\begin{array}{l}\text { NZB,MBNR,NLG,VIZIA,VIZ } \\
\text { AG,YSR,ANTPR }\end{array}$ & $\begin{array}{l}\text { ADB,MDK,NLG, VIZIA,VIZA } \\
\text { G,YSR }\end{array}$ \\
\hline Graduate & PRKSM,YSR,ANTPR & MBNR,YSR,KRNL,ANTPR & $\begin{array}{l}\text { MDK,MBNR,PRKSM,YSR,A } \\
\text { NTPR }\end{array}$ \\
\hline \multicolumn{4}{|c|}{ Urban(Moderately Poor Level) } \\
\hline Primary & $\begin{array}{l}\text { MDK,RR,WGL,SRKLM,GNTR, } \\
\text { PRKSM }\end{array}$ & NLG & ADB,HYD,MBNR \\
\hline Middle & MDK,MBNR,WGL,GNTR,YSR & $\begin{array}{l}\text { KNR,MBNR,SRKLM,VIZIA, } \\
\text { PRKSM }\end{array}$ & NZB,HYD,GNTR \\
\hline Secondary & $\begin{array}{l}\text { NZB,MBNR,VIZIA,VIZAG,PRK } \\
\text { SM,ANTPR }\end{array}$ & KNR,MDK & NZB,MBNR,VIZAG,NLR \\
\hline Pre-Univ & $\begin{array}{l}\text { MBNR,NLG,WGL,SRKLM,VIZI } \\
\text { A,VIZAG,PRKSM,KRNL }\end{array}$ & $\begin{array}{l}\text { NLG,SRKLM,VIZIA,PRKSM } \\
\text {,YSR,KRNL }\end{array}$ & $\begin{array}{l}\text { ADB,KHMM,VIZIA,EG,KRN } \\
\text { L,ANTPR }\end{array}$ \\
\hline Graduate & $\begin{array}{l}\text { WGL,KHMM,SRKLM,PRKSM, } \\
\text { YSR,KRNL,ANTPR }\end{array}$ & $\begin{array}{l}\text { MDK,WGL,VIZIA,PRKSM,K } \\
\text { RNL,ANTPR }\end{array}$ & $\begin{array}{l}\text { NZB,KNR,MDK,MBNR,WGL } \\
\text {,VIZIA,KRNL,ANTPR }\end{array}$ \\
\hline
\end{tabular}

Table 4: The districts exhibited Moderately Poor Level of Education over the period of two decades

\section{CONCLUSIONS}

For decline of any ratio, the possible reasons are the following.

1. Decline in women population comparatively i.e., decline in the sex ratio in that particular age group.

2. People of that age group might have migrated for higher education to other districts.

When Urban \& Rural areas are compared, there is no much change in the patterns, except for one or two districts at all education levels. Education awareness programs are to be conducted in the backward districts in Rural and Urban areas.

\section{ACKNOWLEDGEMENTS:}

The authors are grateful to the Data Dissemination Section, Directorate of Census Operations, Govt. of Andhra Pradesh \& Telangana, for providing the data.

\section{REFERENCES}

[1] Douglas C. Montgomery (2008): Introduction to Statistical Quality Control, $6^{\text {th }}$ Edition - , John Wiley \& Sons, Inc.

[2] https://en.wikipedia.org/wiki/Literacy_in_India

[3] https://en.wikipedia.org/wiki/Indian_states_ranking_by_literacy_rate 